\title{
Warrnambool Exchange Fire - Resilience and Emergency Management
}

\author{
Mark A Gregory \\ RMIT University, mark.gregory@rmit.edu.au \\ Kaye Scholfield \\ RMIT University, kaye.scholfield@rmit.edu.au \\ Khandakar Ahmed \\ RMIT University, khandakar.ahmed@rmit.edu.au \\ Dorothy McLaren \\ RMIT University, dorothy.mclaren@rmit.edu.au \\ James Williams \\ RMIT University, james.williams@rmit.edu.au \\ Helen Marshall \\ RMIT University, helen.marshall@rmit.edu.au
}

\begin{abstract}
Summary: Effective emergency management of a disaster at a single point of failure is vital if the effects of the disaster are to be mitigated. The immediate impacts of a disaster highlight stakeholder perspectives. There is no one-size-fits-all solution to every disaster. Nevertheless, analysing features, aftermath, impact and interim services made available after a disaster provide lessons that can be utilised to avert or mitigate the effects of similar events in the future. This paper provides lessons learnt from the a fire that occurred in 2012 in the Warrnambool telephone exchange located in Victoria, Australia and proposes a strategy that provides increased network resilience and more effective emergency management once the copper-based core switching in exchanges is progressively replaced by fibre service area modules.
\end{abstract}

\section{Introduction}

A fire occurred on November 22, 2012 at 4.35 AM in the vicinity of the Maintenance Control Room at Telstra's Warrnambool Exchange building in Victoria, Australia. The exchange acts as a transmission hub for telecommunications connecting about 100,000 people from South West Victoria, about 15,000 square kilometres. Within four minutes of the fire alarm, the local fire fighters were on the scene; however, by the time fire was put out, it had caused significant damage to essential telecommunication equipment. The cable connection between the Telephony and Broadband Communications Equipment and the Main Distribution Frame, and other internal building cables connecting the site to the remainder of the Telstra network, were destroyed. The Warrnambool Exchange is a single point of failure for much of the 
telecommunications infrastructure in the region, and the fire led to the loss or degradation of regional telecommunication services for up to 20 days (Gregory \& Scholfield 2013).

\section{A. Immediate aftermath}

Telstra's Major Incident Management group released an immediate initial assessment at 5.46 AM on 22 November 2012 and a final fire investigation report on 27 March 2013. Services impacted included:

- 61,856 PSTN telephony services

- 14,409 ADSL services and consumer broadband

- 56 ISDN services

- 40 3G-Mobile Base Stations

- 138 Metropolitan Area Network (IPMAN) services

- 13 Telstra Internet Direct services

- Multi Service Edge Router failure (Impact summary 268 x Business DSL, 16,094 x ADSL, 4 x Internal use Frame Relay/ATM, 47 x Frame Relay/ATM, 40 x 3G Mobile Base Stations)

- Specialised Mobile Radio (SMR) services, Loss of all Radio Coverage Warrnambool \& Port Campbell

- Loss of communications to Digital Video Network equipment at Warnambool \& Terang node for Sky Racing (Television feed to horse racing track)

\section{B. Impact from different perspectives}

The economic and social impacts on three broadly defined groups - local businesses, community service providers and individuals - varied across the affected region surrounding Warrnambool, a city with a population of approximately 33,000. The estimated daily economic impact of a complete telecommunication outage to Warrnambool city was estimated to be up to $\$ 0.4$ million per day in the worst case or approximately 5 per cent of its daily economic output. The direct cost to the Great South West Coast region was estimated to be up to $\$ 0.95$ million per day, or approximately 3 per cent of the region's daily output (DBCDE 2013). The financial effect on the community appear to have been greater than initial reports due to financial claims continuing after investigative reports were published (Gregory \& Scholfield 2013; International 2013). 


\section{1) Local Businesses}

In modern society, business relies upon electronic financial transactions carried out using online banking or EFTPOS. However, due to the outage, local businesses were unable to utilise any form of electronic financial transactions resulting in reduced business activity and missed commercial opportunities. Utility providers reported interruptions in monitoring and controlling essential distributed networked systems. The local tourism industry was negatively impacted by loss of access to online booking systems and customer interaction. The retail sector had reduced activity during the Christmas trading period. The important agricultural sector was unable to retrieve timely information about commodity markets and lost access to its suppliers and customers.

\section{2) Community Service Providers}

Community service providers were severely impacted and lost capacity to manage or coordinate staff and volunteers and to perform otherwise routine activities. The affected community service providers included health and welfare organisations, council and emergency services including ambulance, police and the regional volunteer fire fighting authority which was to play a major role in information dissemination.

\section{3) Individuals}

The impact on individuals was considerable, due to the inability to get funds for commodities or to call work, family and friends or to notify organisations like banks. Casual staff working hours in the retail and health sectors were reduced in some instances and some businesses were forced to cease trading during the outage. People had to travel for up to four hours to find ATMs and return home, to purchase prepaid mobile phone services for the surviving Optus 3G mobile cellular network or to complete other tasks. Elderly people who were living alone, people with telecommunication-connected medical devices and people with health concerns were insecure and found to have increased levels of anxiety and a sense of isolation. Community efforts to mitigate the outage effects on the vulnerable were considerable.

\section{Relevant disasters}

An Australian bushfire, referred to as "Black Saturday" (Teague et al. 2010) on February 7, 2009 took 173 lives, ravaged thousands of hectares of land and burned down hundreds of houses. Eight Telstra regional mobile cellular towers, 2800 fixed phone lines, 2100 ADSL internet connections and 39 ISDN phone lines went out of operation. Telstra invested \$15 million to repair and upgrade its network in the affected areas. During that time, Telstra installed four new exchanges in Marysville, Narbethong, Kinglake and Kinglake West, and built new mobile cellular network base stations to provide permanent and improved mobile 
coverage to the affected areas. Whilst this disaster affected a much smaller region than that affected by the Warrnambool Exchange fire, the loss of infrastructure meant a similar widespread loss of telecommunications services until the infrastructure was rebuilt or replaced by portable systems.

Queensland, another Australian State, experienced a series of natural disasters during the summer of 2010-11 with the destruction wrought by Severe Tropical Cyclone Yasi (Boughton et al. 2011). The entire state, 1,727,000 square kilometres, was declared disaster affected with the tragic death of 37 people. 159 Telstra mobile cellular network sites, 60 GSM mobile sites, 94000 fixed line services and 32000 ADSL broadband services were disrupted and went out of service for periods that in some areas lasted weeks.

The Warrnambool Exchange fire, followed by the network outage affecting 100,00o people of South West Victoria, was quite different from a natural disaster. In contrast to a natural disaster, the Warrnambool and surrounding communities were affected only by the loss of telecommunications, and community life continued unabated: most businesses still opened, homes were still occupied, roads and other infrastructure were operational. There was no lead time for preparations to be made and contingency plans to be deployed. The impact and consequences of the event for people and organisations outside the affected area ranged from no disturbance at all if interaction with people and organisations within the affected area was not required, through to significant disturbances to commercial life, personal interactions and communications with people, businesses and government within the affected region.

Incidents of large scale loss of service due to the partial or complete destruction of a telecommunications exchange are relatively rare events. In May 2011 an incident similar to the Warrnambool Exchange fire was reported in Malaga, Spain (Movistar 2011). It was suspected that the fire was ignited by lightning.

On 8 May, 1988, a fire occurred in the main switching room of the Hinsdale Central Office of the Illinois Bell telephone company (FTIC 1989). It was one of the largest switching systems in the state, connecting 38,00o customers including hospitals, business and Chicago's O'Hare and Midway Airports. Each day, the facility was used to process 3.5 million calls. The aftermath of the fire at the centre was significant at Hinsdale and the surrounding regions. Telephone service was lost for almost 40,00o local phone lines. Illinois Bell took two weeks to completely restore telephone service for the affected region.

On 18 July, 2001, a 60 car CSX transportation freight train derailment occurred in a freight through-route tunnel under Howard Street in Baltimore, Maryland. The Howard Street tunnel housed an Internet pipe serving seven of the biggest US Internet Information Services Providers (ISPs). The fire burned through the pipe and damaged these cables which were used 
for voice and data transmission, causing backbone slowdowns for ISPs such as Metromedia Fiber Network, Inc., WorldCom, Inc., and PSINet, Inc (Wikipedia 2001).

Fifty years ago, on 22 September, 1961, an incident of a similar nature was recorded in the Canberra suburb of Civic, Australia (DBCDE 2013). In that event, a telephone exchange was damaged destroying 5,402 fixed line telephone services. The cause of the fire remains unknown. To restore this exchange, 200 skilled people worked 12-hour shifts to install new equipment in temporary facilities. The restoration process took seven weeks to be completed.

\section{Social Impact Assessment}

Two surveys and several community discussion group sessions were carried out in order to assess the impact of the Warrnambool Exchange fire (Gregory \& Scholfield 2013). An online survey was not possible, so paper-based surveys were printed, distributed and collected. In addition, cards with the survey address were printed and distributed inviting people to go online once their Internet service resumed. Media and community partners assisted in raising awareness of the research. Initial surveys from residents in South West Victoria were collected between December 2012 and the late January 2013. A survey conducted in the second half of 2013 focused on how the loss of telecommunications connected devices affected people.

The survey questions were grouped into sections which provided respondents with the opportunity to comment on how the outage affected different aspects of their lives.

Personal (non-identifiable) demographic and geographic information was collected, including a section that identified the response as being from the perspective of an individual, business owner/operator, community member or other (as specified). Those who wished to respond from more than one perspective were asked to fill in separate surveys for each category. Length of disruption (in days) was canvassed for landlines, mobile phones and internet access, with capacity to nominate differing lengths of disruption per item. The nature of communication disruptions was identified as either friends/family related or business related, with the opportunity to comment further if desired.

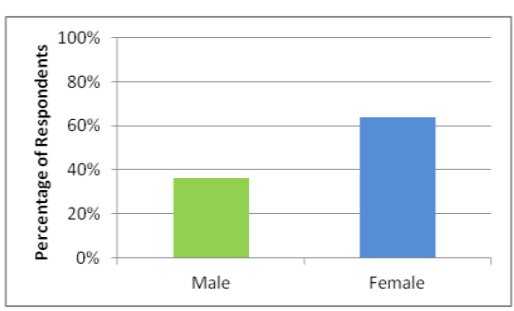

(a)

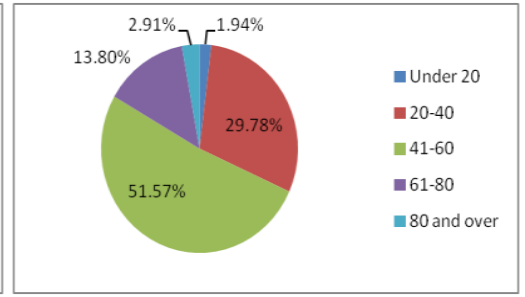

(b)

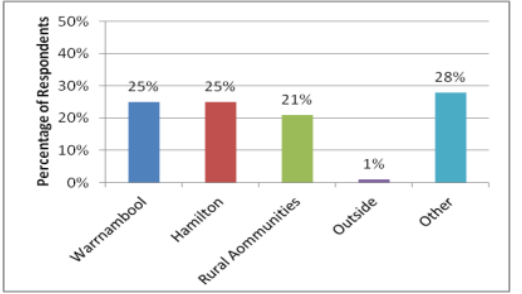

(c)

Figure 1 - Personal demographic and geographic information: a) Gender b) Age Group 3) Demography 
Impact on business and commerce was surveyed with questions regarding retail and workrelated concerns. Respondents were invited to tick boxes if they had found it difficult or impossible to make essential purchases (food and fuel), pay bills or make bookings. For those who were regularly employed, information was sought as to the impact on their usual place of work, particularly inability to conduct business (shut down), reduced ability to process orders, loss of customers or difficulty in conducting tasks (such as accessing email). In each case, additional comments were also invited.

Health and health-related concerns were canvassed, including both actual health emergencies and concerns for health and safety due to the outage, through both specific questions and comment boxes. General comments were also sought regarding impact on community life and any positive impacts arising from the lack of telecommunications. Estimates of financial cost were sought with tick boxes for specific dollar amounts and, again, the opportunity to comment more broadly.

Two questions invited comments on non-essential activities that people would have liked to do but were unable to, and activities that people really needed to do but were unable to, because of the outage. Planning for the future was also queried, and respondents were asked to identify whether or not they had begun to think about and plan for the potential for other, similar, events in the future. This included an invitation to elaborate on alternative or future plans. Finally, the opportunity to make other comments was offered.

The responses received reflected the geographic spread of the population across the affected region and the particular business and personal interests of each respondent. There was a lower response from the northern areas possibly because the greatest effect was in Warrnambool and its immediate surroundings. Approximately 50\% of the responses were divided equally between Warrnambool and Hamilton, the region's second largest city. 21\% of responses were from rural communities and small towns of less than 1,000 residents. Just $1 \%$ of the responses were from people outside of the affected area. The smaller communities of Colac and Portland provided 5\% of total responses. Two thirds of respondents were female with the largest number (138) being from females aged between 41 and 6o. A survey data set was processed using NVivo1o (QSR International 2013) and the survey questions were then coded to create sub-categories or themes. The analysis showed recurring themes including work, access to money, health and safety, communication and impact on the community.

\section{Steps taken in the immediate aftermath}

The response and restoration process in any disaster involves the provision of an interim service and a permanent solution. Telstra, the owner and operator of the Warrnambool Exchange, provided both. 


\section{A. Interim Service}

Telstra deployed Mobile Cells on Wheels (COW), Mobile Exchanges on Wheels (MEOW) and Satellite COWs (SatCOWs) to provide interim services to some customers, including emergency service organisations, some hospitals and some priority assistance customers (Piltz 2013).

All cellular mobile services, including non-Telstra customers, received access to the Triple Zero service (911) as Telstra rebuilt the mobile cellular network connectivity as a priority. However, customers without a mobile remained isolated and unable to access emergency services. Additionally, Telstra deployed satellite phones to emergency service locations and distributed interim mobile and satellite phones to customers based on a medical priority list.

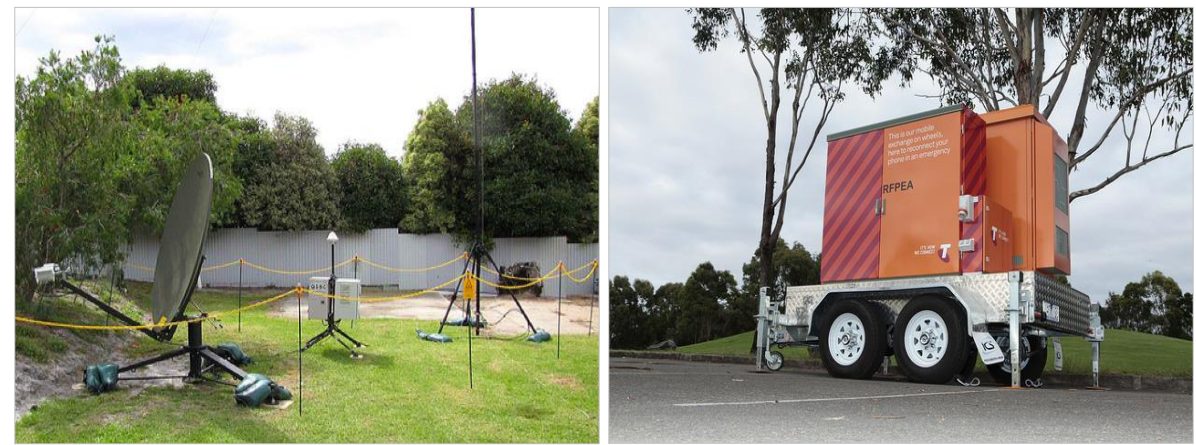

Figure 2 - a) Satellite Cells on Wheels b) Mobile Exchange on Wheels, Source: (Piltz 2013)

\section{B. Long Term Restoration}

In restoring the Warrnambool Exchange, Telstra followed a similar approach to that adopted for other recent disasters, such as the Victorian "Black Saturday" Bushfires in 2009 (Teague et al. 2010), Cyclone Yasi in 2010 (Boughton et al. 2011) and the Victorian floods of 2011 (Comrie 2011). This approach is based on 3 day, 3 week and 3 month horizons for restoring services. Telstra utilised 110 highly skilled technicians working rotating 12 hour shifts under the guidance of design, data configuration, logistics and project management experts. The complete restoration process took three weeks and was completed on Wednesday 19 December 2012. Telstra's operations groups including Service Delivery, Network Construction, Network and Access Technologies and Network and IT operations worked together coordinated by the Telstra Global Operations Centre to achieve restoration in the following sequence (Piltz 2013): 


\section{1) Building services restoration}

The very first restoration step was taken immediately after Telstra regained access to the exchange. Temporary facility access and roofing, provision of power and lighting were completed on the first day.

This initial building restoration work provided the repair teams with an environment within which they could access and temporarily repair other services such as air-conditioning.

\section{2) Transmission equipment}

The opening step towards restoring telecommunication services was the complicated transmission equipment repair. This included repairing or replacing parts of the transmission equipment and fixing cabling within equipment racks. As the transmission equipment supports the functionality of other services customer services remained unaffected at this stage.

\section{3) Data node and mobile service restoration}

The next focus area was the data node (IP based routing). Once the transmission equipment and associated cables were interconnected the IP routing equipment provisioning became available for the restoration of limited data and mobile cellular services.

The next restoration step was the repairing or replacing links to the adjoining and remote mobile cellular base stations and this work commenced on 23 November 2012. The reconnection of directly connected mobile base stations needed the cabling within the exchange to be restored. The data node was also required to be connected to the exchange transmission equipment.

By the end of this step, mobile cellular voice services started functioning as regional mobile cellular base stations were reconnected, tested and put into an operational state. At this time some of the internet and other data services were also restored as cabling was recommissioned and tested. According to Figure 3(a), all of the mobile cellular base stations were restored within the period 22 to 29 November 2013.

During that time, the older Optus $3 \mathrm{G}$ mobile cellular sites were in operation due to this network connecting to a different transit point. Mobile devices within range of the Optus network were able to access Triple Zero services. However, the Optus network was quickly swamped during peak times when people realised it was operational and rushed to get prepaid access to this network. 


\section{4) Restoration of call switching capabilities}

Re-parenting of PSTN services to South Melbourne, the upstream exchange, was commenced on 25 November 2014. Other than restoring the core telephony switch, PSTN switching for Warrnambool and surrounding smaller exchanges were rerouted to a central switch in South Melbourne by using the restored transmission equipment and reconfiguring the Ericsson AXE exchange at Warrnambool. By taking this action Telstra reduced the restoration time necessary to return full service to the region.

As illustrated in Figure 3(b), within a six day period from 25 to 30 November 2012, 92 per cent of PSTN services were restored. However, it took another seven days to restore the remaining 5000 PSTN services.

\section{5) Restoration of Internet services}

Restoration of Internet services was the last major activity undertaken. This involved replacing the destroyed DSLAMs and terminal equipment within the Warrnambool Exchange.

Figure 3(c) shows how the internet service restoration progressed for an initial period and then had a delay before further restoration occurred due to other restoration activities. The timing of the internet service restoration was linked to the reconnection of remote exchanges and the rerouting of PSTN services.

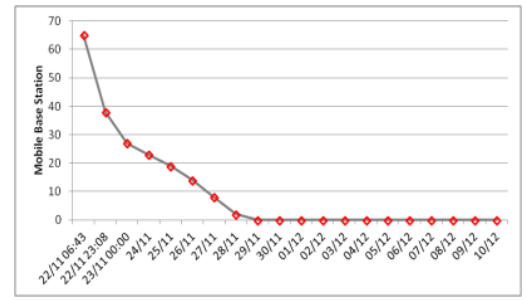

(a)

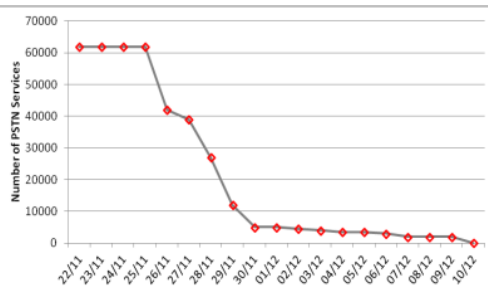

(b)

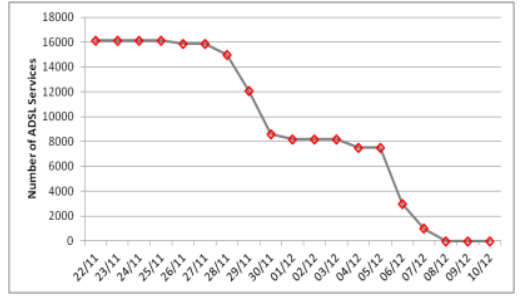

(c)

Figure 3 - a) Mobile Base Station Restoration Timeline b) Timeline of PSTN Service Restoration c) Timeline for ADSL Service Restoration, Source: (Piltz 2013)

\section{6) Customer reconnection prioritisation}

A few high priority customers were provided with telecommunication services in the first few days by deploying temporary telecommunications facilities. Telstra identified the customers during consultations with police, fire, health, human services, local hospitals, aged facilities and the local council.

Cellular mobile service restoration was the priority activity for teams working within the Warrnambool Exchange. The opportunity to restore mobile cellular within the region was 
identified as vital to restoring region wide telecommunications coverage. From the technical perspective this early restoration of mobile cellular services had several advantages including:

- The least amount of equipment restoration and cabling repair required within the Warrnambool Exchange. (Transmission and limited fibre cables)

- The central cellular switch is not located within the exchange building.

- All terminal equipment is located at the base stations remote to the building.

- Temporary (MEOW \& COW) solutions are already in service and can be integrated.

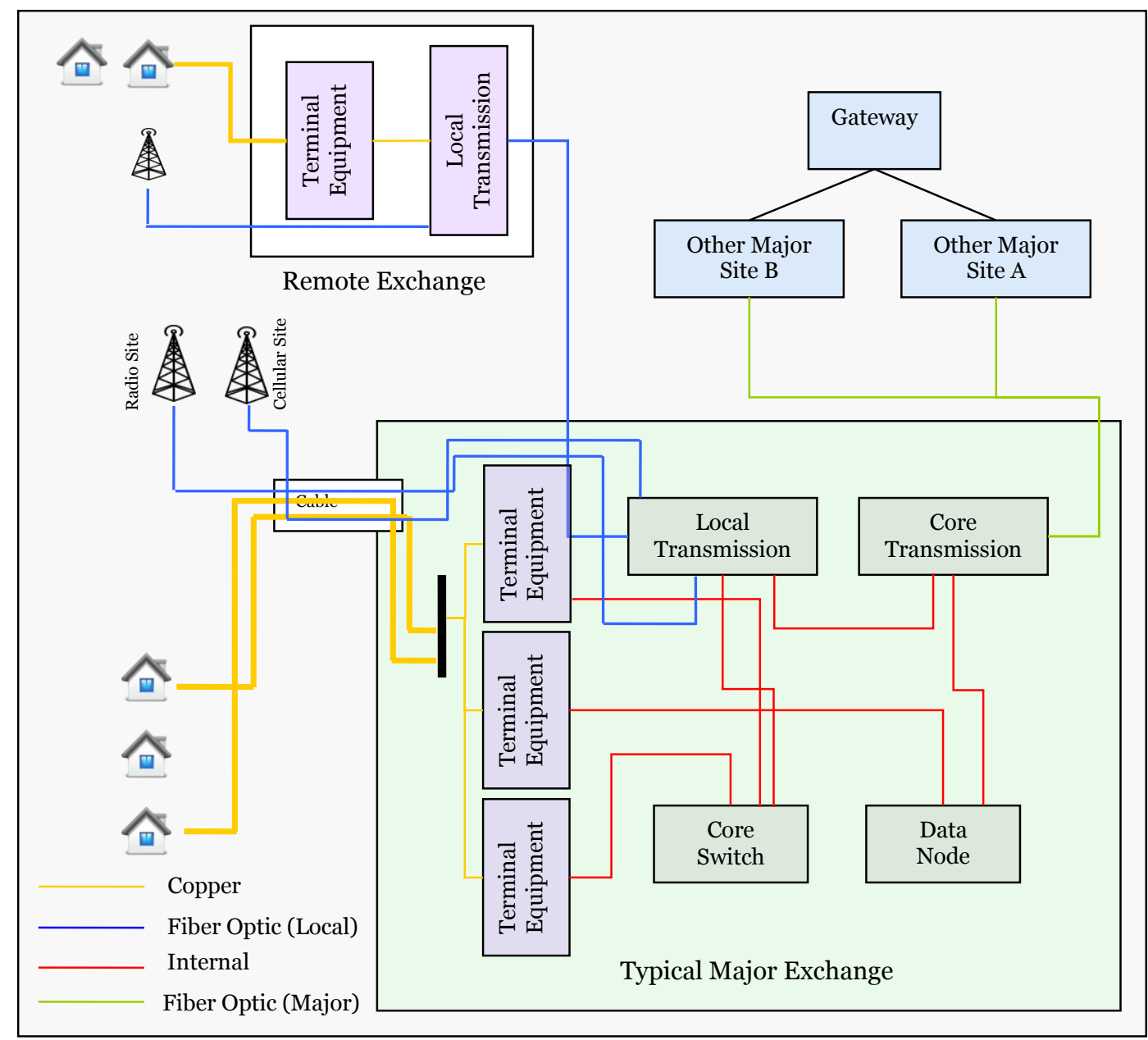

Figure 4 - Typical Major Exchange Equipment, Source: Telstra

\section{Typical exchange architecture}

Telstra reported that the incident caused damage to equipment which included

i) transmission equipment,

ii) ii) core telephony switch,

iii) iii) data node,

iv) iv) terminating equipment, 
v) v) external cables, and

vi) vi) internal cables,

as shown in Figure 4.

\section{A. Transmission equipment}

Transmission equipment uses optic fibre or radio systems to provide connections beyond the exchange building.

The transmission equipment was considered in two functional groups: core transmission equipment, which provides connection from the major exchange to the backhaul network, and local transmission equipment, which provides a connection from the exchange to the remote regional exchanges. The local and core transmission equipment is also connected to the central switch and data node within the major exchange.

For a major exchange, redundant transmission equipment is installed so that an alternative path is available to maintain service in the event of any element failing. In the Warrnambool Exchange fire the redundant transmission equipment also failed, resulting in a total loss of transmission capability that impacted all data and voice services.

\section{B. Core telephony switch}

Core telephony switches enable establishment of a connection path between two parties. Modern fixed telephone networks are based on a limited number of core switches located in major exchanges. Although terminal equipment contains limited switching capability, in most cases the core switch is required to establish a connection path.

A core telephony switch is generally not duplicated in an alternative location. However, within a core switch, the hardware elements are typically duplicated. This means that any single card or device fault will not interrupt service.

The core telephony switches in the Warrnambool Exchange supported the local and regional terminal equipment. The fire damaged the core switches (including the duplicate hardware elements), rendering it impossible to connect voice calls from remote and local terminal equipment.

\section{Data node}

The data node routes all data services to the correct location, including IP management, cellular data, Internet, EFTPOS and xDSL services. Failure of the data node prevents routing of data services connected to terminal equipment in the major exchange and in remote exchanges. It also includes loss of connectivity for cellular data. 
Similar to the core telephony switch, individual components of a data node are duplicated and any single fault will not cause system outage, but the Warrnambool Exchange fire caused both equipment and redundant equipment failure.

\section{Terminal equipment}

The terminal equipment comprises copper line termination (CLT) devices and optical line termination (OLT) devices. For a copper network, a CLT converts the signal from analogue to digital, and for a fibre network, the OLT converts the signal from electrical digital to light. The digital signal is then sent to either the core telephony switch to connect a call, or the data node to receive routing information. The local transmission equipment carries signals from remote exchange terminal equipment to the core switch and the data node.

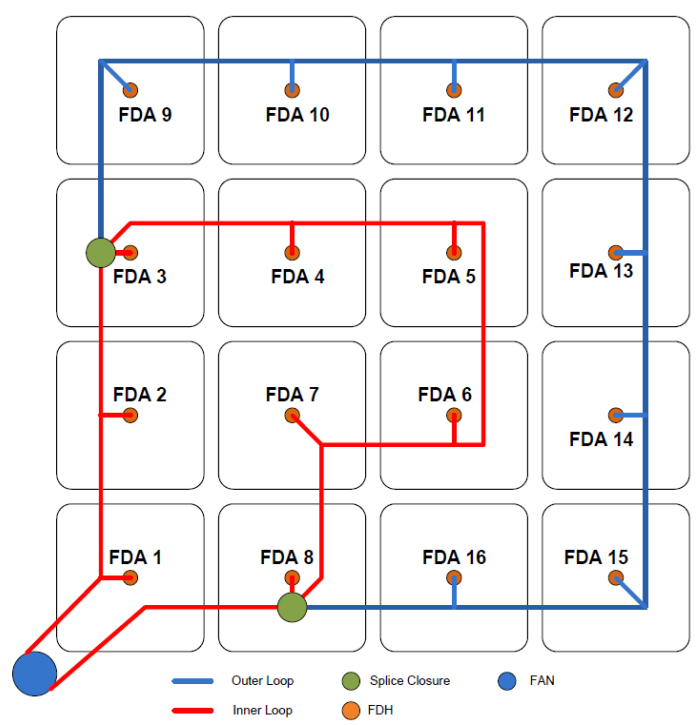

(a) Schematic diagram of Fibre Service Area Module

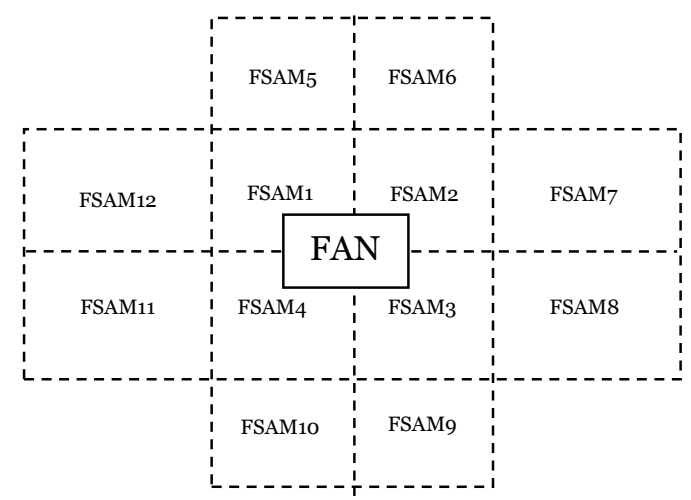

(b) Fibre Serving Area 


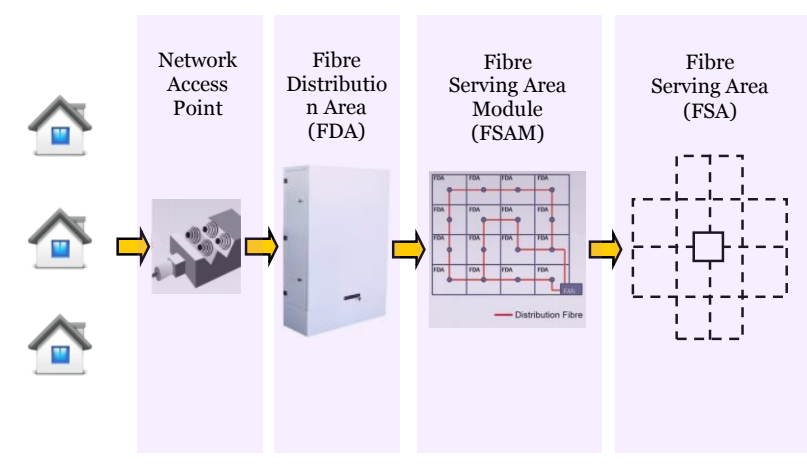

(c) Network Design Replicating Module

Figure 5 - a) Schematic diagram of Fibre Service Area Module b) Fibre Serving Area c) Network Design Replicating Module, Source: (Ferris 2011)

Voice terminal equipment may provide limited switching capability. In general, voice terminal equipment comprises one or more terminal switching stages, with each stage catering for 5002,000 services. In the event the terminal switching stage is disconnected from the core telephony switch, sufficient capability may remain within the terminal switching stage to enable voice calls to other services connected to the same stage.

However, if the voice call is between a customer on one switching stage and a customer on another terminal unit, or a mobile service, or outside of the region, the call must traverse the core switch. As stated above, if the core switches are not operational, most calls cannot be connected.

Terminal equipment, either within the same device as voice or as separate equipment, also provides data capability. In general, it includes equipment for the provision of ADSL and other data service equipment. However, unlike with voice services, terminal equipment used to deliver data services requires a connection to the data core in the major exchange in order to operate.

\section{E. External cable}

Multiple cables of both copper and optic fibre enter a typical major exchange. Copper cables provide connection of fixed line services (telephony and lower speed data) to homes and businesses. Optic fibre cables provide high speed data services to some business customers, links to cellular bases, remote exchanges and special services such as Sky Racing. Optic fibre cables are also used for core network cables that provide connections between major exchanges. Typically, critical cables enter an exchange such as Warrnambool in different places and occupy different locations on the street to prevent the cables being damaged by the same event. 


\section{F. Internal cable}

Within the exchange building, many cables are used to interconnect the various functional elements, and to connect the functional elements to the point where external cables terminate. Internal cabling is normally installed on cable trays suspended from ceilings or beneath raised floors. In both cases, the cables are combined and follow limited routes within the building. These internal cables are essential for the provision of services. The internal cables are represented in red in Figure 4.

\section{Container-based resilient approach}

Improving network resilience, which is the ability to provide and maintain an acceptable level of service in the event of network degradation, is an important focus for network planners and the Warrnambool Exchange fire demonstrates that, at times, planning can be outweighed by events.

Future planning for a resilient network should include identification of new resilient technologies, resilient network designs and how infrastructure can be built and utilised to provide increased resilience to combat a range of events such as a major fire or natural disaster.

Modern telecommunication networks retain infrastructure single points of failure due to the cost and complexity of duplication when the single point of failure is a major facility such as a regional telephone exchange. The trade-off between improved network resilience and the practicalities of network design and operation often leads to compromises that may result in the strategic acceptance of single points of failure existing within a network.

Australia, similar to many other nations, is using more optical fibre in its access networks, which reduces the cabling and equipment found within a typical major exchange. The introduction of fibre into access networks decreases the amount of cabling that typically enters a typical major exchange building and as the fibre is brought into the exchange there is an opportunity to improve network resilience by adopting an approach that provides faster service restoration capability in the event of a major fire or some other natural disaster that affects the serviceability of the exchange infrastructure and internal systems.

Containerisation of key telecommunication systems including access network termination, aggregation and transit systems would provide a vital capability that could be deployed to enhance or replace existing facilities in the event of a major infrastructure failure. The use of COWs, MEOWs and SatCOWs has now become common place, not only to enhance network capability for special sporting or other social events, but also to replace capability destroyed in a natural disaster. 
In the case of the South West Victoria region, the Warrnambool Exchange is a single point of failure that hosts backhaul link endpoints, aggregation and access network technologies. As the Australian national broadband network brings about a change in the access network technologies there will be a reduction in copper utilisation and an increase in the use of fibre within the access network. Access network copper feeder cables connecting consumers to access, aggregation and backhaul within the Warrnambool Exchange will be replaced with fibre over the next five to ten years.

As an example of how containerisation of key systems would improve resilience consider a fibre to the premises access network. Figure 5 (a) shows a typical Fibre Service Area Module (FSAM). By moving away from copper to an all or partial fibre access network, the exchange could be redesigned, as shown in Figure 6, in such a way that the Fibre Access Node (FAN) and FSAM modules (Ferris 2011) could be caged into one or more containers. In this scenario the point of interconnect is the container and the fibre entering and leaving the building would terminate at the containers.

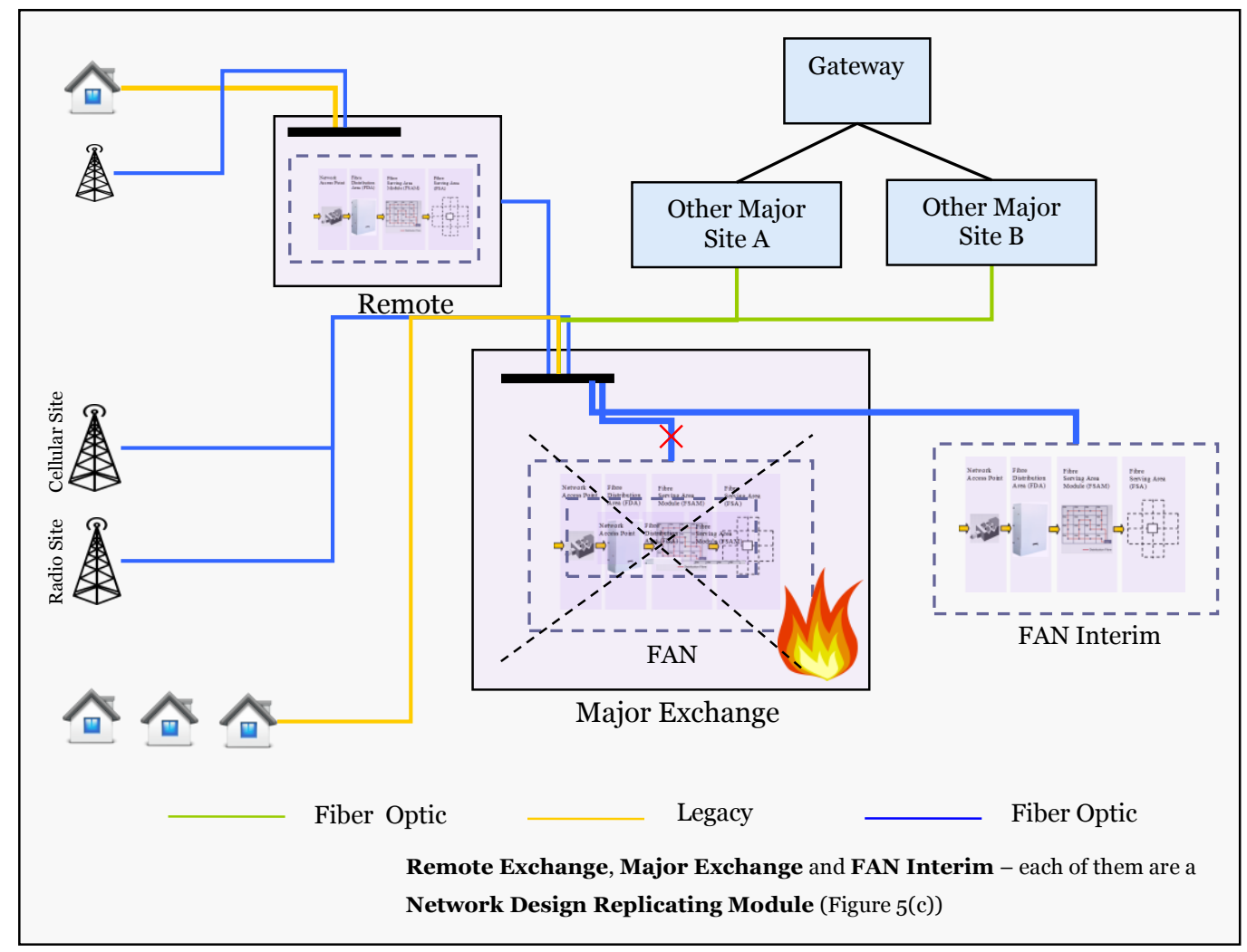

Figure 6 - Proposed Architecture of a Major Exchange

In the situation where an exchange hosts a FSAM, which consists of a series of up to 16 Fibre Distribution Areas (FDA) that are linked by fibre in a double loop configuration. A single fibre sheath connects the FSAM and Fibre Distributions Hubs (maximum 16) to a nominated FAN. A single fibre sheath is typically $21 \mathrm{~mm}$ thick and contains 312 cores with separate tubes for distribution, trunk, GPON or Ethernet and P2P fibres. An FSAM may cover a small town or a 
part of suburb in the case of large cities. Approximately 2000 to 3000 premises could be accommodated depending on the location and network planning or topology.

The FAN houses active equipment to service a FSA. Fibres from the FDHs are terminated in the FAN using high density fibre distribution management frames before being used as input to 2.5 GPON line cards or 10 GPON line cards. If the building is destroyed then a new interim mobile container could be brought in and placed adjacent to the destroyed building. The external fibre cables could be patched and rerouted into the replacement container providing immediate service restoration.

A key reason why this approach is more suitable for the restoration of an all or partial optical access network is the reduction in cabling from the more than 250,000 copper pair entering the Warrnambool exchange to what could be less than 10,000 fibres necessary to support an all or partial optical access network for a region the size of South West Victoria. Also the task of restoring the facility can be delayed whilst the interim mobile container is brought online.

Similar to the approach presented to restore fibre networks, the mobile cellular networks are already geared towards central switching and could be readily restored utilising exchanges on wheels or containerisation. There is a synergy that can be leveraged as the shift from copper to fibre access networks occurs and this will significantly enhance network resiliency and emergency management efficiency.

\section{Conclusion}

Presented in this paper is a practical strategy for enhancing emergency management and network resiliency as the shift from copper to all or partial optical access networks occurs. Existing copper access networks are problematic for any shift to a more resilient network due to their age and design but with the onset of all- or partially-optical access networks there is an opportunity to design infrastructure installations for a more resilient operation and faster restoration if a disaster occurs at an infrastructure single point of failure. The Warrnambool Exchange fire provided an opportunity to closely review the effects of a single point of failure being destroyed by fire and the service restoration that followed. The research findings highlighted the need to reduce the impact of infrastructure single point of failure disasters by moving to an infrastructure build approach that permits duplicated containerised facilities containing key telecommunication systems to be installed and made operational quickly.

\section{Acknowledgements}

This work was supported by a 2013 Research grant from the Australian Communications Consumer Action Network: 'Warrnambool Exchange Fire Consumer Impact Analysis'. 


\section{References}

Boughton, G.N; Henderson, D.J; Ginger, J.D; Holmes, J.D.; Walker, G.R.; Leitch, C.J.; Somerville, L.R.; Frye, U.; Jayasinghe, N.C.; Kim, P.Y. 2011. Tropical Cyclone Yasi -Structural damage to buildings. CTS Technical Report No 57, Cyclone Testing Station School of Engineering and Physical Sciences James Cook University Queensland Available from: https://www.jcu.edu.au/cts/publications/content/technical-reports/jcu078421.pdf/at download/file.

Comrie, Neil. 2011. Review of the 2010-11 Flood Warnings \& Response. Available from: http://www.floodsreview.vic.gov.au/about-the-review/final-report.html

DBCDE. 2013. Inquiry to learn lessons from the Warrnambool exchange fire [cited February 2014]. Available from: http://apo.org.au/files/docs/DBCDE WarrnamboolInquiryLessons June2013.pdf.

Ferris, Peter. 2011. NBN Co. Briefing Engineers Australia - Sydney Division

FTIC. 1989. Hinsdale Central Office Fire Final Report 1989 [cited March 1989]. Available from:

https://www.google.com.au/url?sa=t\&rct=j\&q=\&esrc=s\&source=web\&cd=2\&cad=rja\&ua ct $=8 \& v e d=0 C C k Q F j A B \& u r l=h t t p \% 3 \mathrm{~A} \% 2 \mathrm{~F} \% 2 \mathrm{Fwww}$.telephonecollectors.info\%2Findex.ph p\%2Fdocument-repository\%2Fdoc download\%2F12082-the-hinsdale-challenge-1988executivesummary\&ei=3 wHVMr8K8W8ugS oYCQCg\&usg=AFQjCNFNa3g1jgCPPXos7iDIjceyvu -KnQ\&sig2=ECdZpb3sUiuID2XYIkrQ-g\&bvm=bv.74649129,d.c2E.

Gregory, Mark A; Scholfield, Kaye. 2013. Warrnambool Exchange Fire Consumer Impact Analysis. [cited February 2014]. Available from: https://accan.org.au/grants/completedgrants/623-warrnambool-exchange-fire-consumer-impact-analysis

QSR International. 2013. NVivo. [cited February 2014]. Available from: http://www.qsrinternational.com/products nvivo.aspx

Movistar. 2011.Fïre in Telefonica Exchange in Malaga. 123 Marbella Internet Services, Sunday, May 8th, 2011. Available from: https://www.123marbella.co.uk/fire-intelefonica-exchange/.

Piltz, David. 2013. Warrnambool Exchange Fire Investigation Report, Telstra Corporation Limited.

Teague, Bernard; Mcleod, Ronald; Pascoe, Susan. 2010. 2009 Victorian Bushfires Royal Commission Final Report Summary [cited February 2014]. Available from: http://www.royalcommission.vic.gov.au/finaldocuments/summary/PF/VBRC Summary PF.pdf

Wikipedia. 2001. Howard Street Tunnel Fire, [cited February 2014]. Available from http://en.wikipedia.org/wiki/Howard Street Tunnel fire 